\title{
Development of Ni-doped Yttria stabilized Zirconia composite for SOFC applications as Anodic material
}

\author{
V. Mohanta, S.K. Das, B.K. Roul \\ Institute of Materials Science, Planetarium Building, Acharya Vihar, Bhubaneswar-751013, Odisha, India
}

\begin{abstract}
Ni-doped Yttria stabilized Zirconia (NiO/YSZ) has been synthesized using low cost combustion process from an aqueous solution containing $\mathrm{ZrO}\left(\mathrm{NO}_{3}\right)_{2} \cdot 6 \mathrm{H}_{2} \mathrm{O}, \mathrm{Y}\left(\mathrm{NO}_{3}\right)_{3} \cdot 6 \mathrm{H}_{2} \mathrm{O}, \mathrm{Ni}\left(\mathrm{NO}_{3}\right)_{2} \cdot 6 \mathrm{H}_{2} \mathrm{O}$ and urea. Pellets were sintered at $1350^{\circ} \mathrm{C}$ for 5 hours and its sintered density is estimated to be of $95 \%$. Sintered pellets were characterized using X-ray diffraction (XRD), scanning electron microscopy (SEM) \& X-ray photoelectron spectroscopy (XPS) techniques. From the XRD analysis, as grown powder of NiO/YSZ showed nano-crystalline behavior with homogeneous mixture of YSZ and NiO phases. However sintered powder showed $\mu$-size dense grain growth. Temperature and frequency dependent dielectric properties are corroborated with the conduction mechanism. Both dielectric constant $(K)$ and loss (tan $\delta$ ) are increased sharply at high temperature region, which is expected to be the onset of dipolar relaxation phenomena due to the presence of oxygen vacancies. A mixed conductivity involving ionic conduction in the high temperature range and electronic conduction in the low temperature range was observed. The decrease in $K$ and tan $\delta$ with increase in frequency at a given temperature suggests the dynamic interaction of oxygen vacancies \& oxide ion pairs.
\end{abstract}

Keywords: NiO/YSZ composite, Combustion process, Dielectric properties, Mixed conductivity, SOFCs.

\section{Introduction}

Solid oxide fuel cell (SOFC) is an electrochemical device which converts chemical energy directly to electricity with high efficiency and zero harmful emission [1]. At present, SOFCs are one of the most promising energy converters over other types of fuel cells due to their high efficiency, design modularity, fuel flexibility and environmentally friendly nature [2-8]. In SOFC, anode is one of the main components where reforming and electrochemical conversion reaction takes place, which directly influence the performance of an SOFC.

A few problems are associated with anode materials for SOFCs applications i.e., carbon deposition in anode, anodic reaction is limited to double-phase boundary (contact plane) between electrolyte and anode, and electrochemical reaction zone (ERZ) is limited to triple phase boundary. Different materials used for anode are Cu-cerium oxide, doped $\mathrm{SrTiO}_{3}, \mathrm{La}_{0.7} \mathrm{Sr}_{0.3} \mathrm{Cr}_{0.8} \mathrm{Ti}_{0.2} \mathrm{O}_{3}, \mathrm{La}_{0.8} \mathrm{Sr}_{0.2} \mathrm{Cr}_{0.97} \mathrm{~V}_{0.03} \mathrm{O}_{3}$, Ni-doped Yttria stabilized Zirconia (Ni/YSZ) etc [3]. Among all these materials, Ni/YSZ cermets have been extensively used as anode for SOFCs, since it satisfies all the above criteria and its low cost [1,9]. In a Ni/YSZ anode, Ni acts as an excellent reforming catalyst and electro-catalyst for oxidation of fuel as well as provides electronic conductivity, while YSZ acts as a matrix to support Ni particle and prevents Ni from agglomeration under operating conditions, which in turn avoid reduction in triple phase boundary (TPB) and increase in the electrode polarization resistance $[2,7,10]$. The fuel gas meets $\mathrm{Ni}$ passing through pores and YSZ phases to form a triple-phase boundary, where electrochemical reaction takes place. YSZ also used to extend the TPB into the anode by offering ionic contribution to the overall conductivity [2, 11, 12], which ultimately improves the anode performance.

Different methods have been adopted for preparation of Ni/YSZ anode for SOFCs. These are (i) sonochemical preparation, (ii) co-precipitation, (iii) electro-less co-deposition, (iv) hydro-thermal synthesis, (v) spray pyrolysis , (vi) tape casting, (vi) mechanical mixing or ball milling of individual powders followed by compaction and sintering, and (vii) combustion synthesis etc [3, 13]. Since properties of Ni/YSZ anodes are mostly dependent on the particle size and the microstructure of the cermets, among various methods stated above, combustion synthesis is a simple and cost effective to produce very fine, homogeneous with high purity, a narrow particle size distribution with high specific surface area and highly crystalline powders [3,13,14] without any intermediate step. It consists of a self-propagating high temperature synthesis (SHS), discovered by Merzhanov and co-workers, which involves a wide variety of chemical routes and products [14]. In combustion synthesis, nano-powders or loose agglomerates of nano-crystallites are produced in reaching high temperature in a short reaction time by self-generated heat of reaction [2]. Different fuels such as sucrose, glycine, citric acid, carbohydrazide, urea etc., have been used in this method as fuel $[1,3,14]$.

In this research work, $\mathrm{NiO} / \mathrm{YSZ}$ composite material was prepared by combustion route using urea as fuel and followed by sintering at $1350^{\circ} \mathrm{C}$ for 5 hours. The aim of the present investigation is to carry out the frequency and temperature response to the dielectric measurements of the above anode precursor and corroborate the dielectric property with the conduction mechanism. 


\section{Experimental Procedure}

$\mathrm{NiO} / \mathrm{YSZ}$ composite powder has been produced by combustion synthesis using urea as fuel and the

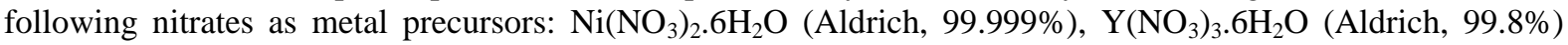
and $\mathrm{ZrO}\left(\mathrm{NO}_{3}\right)_{2} \cdot 6 \mathrm{H}_{2} \mathrm{O}$ (Aldrich, 99.0\%). These materials in the required stoichiometric proportions were calculated as per propellant chemistry wherein the total oxidizing and reducing valences of the precursors and the fuel is zero [13]. The amount of urea was taken twice the theoretical amount as determined by the propellant chemistry, to improve the crystallinity of the resulting powder [2]. The above nitrates and urea were mixed in a silica basin and dissolved in distilled water. The solution is heated on a hot plate. After evaporation of water a thick viscous gel was obtained. The basin was then introduced in a furnace, preheated at $600^{\circ} \mathrm{C}$, where the combustion reaction took place. High temperature reactions were revealed by sudden release of fumes. The typical reaction time was 1 to 2 minutes resulting in dry, fragile foam or loose agglomerates.

These agglomerates were converted to fine powder with mild manual crushing by agate mortar. The pellets of size $8 \mathrm{~mm}$ in diameter and $2 \mathrm{~mm}$ in thickness were obtained from combustioned powder by applying uniaxial pressure of $200 \mathrm{MPa}$. The green pellets were sintered at $1350{ }^{\circ} \mathrm{C}$ for 5 hours with a heating rate of $3{ }^{\circ} \mathrm{C}$ per minute. The sintered pellets were characterized by different characterization techniques. The phase composition and crystal structure were investigated by Bruker (D8) X-ray diffractometer (XRD) with $\mathrm{Cu} \mathrm{K \alpha}$ $(\lambda=1.5406 \AA$ ) radiation. Microstructure was observed by EVO-60 (JEISS) scanning electron microscope. X-ray photo electron spectroscopy measurements were performed by ESCALAB high performance electro spectrometer. Microprocessor controlled programmable LCR meter bridge (QuadTech) was used for dielectric study. The conductivity measurements were carried out as a function of temperature in the range from $300 \mathrm{~K}$ to $600 \mathrm{~K}$ at different frequencies $(1000 \mathrm{k} \mathrm{Hz}, 1200 \mathrm{kHz}, 1400 \mathrm{kHz}, 1600 \mathrm{kHz}, 1800 \mathrm{kHz}, 2000 \mathrm{kHz}$ etc).

\subsection{XRD analysis}

\section{Results And Discussion}

As grown powder of $\mathrm{NiO} / \mathrm{YSZ}$ are observed to be in nano sized form, however sintered specimen at $1350{ }^{\circ} \mathrm{C}$ for 5 hours showed highly crystalline behavior (Fig. 1). The search test program developed by us [15], as well as Rietvelt analysis was carried out for refinement of XRD patterns. The refinement results are given in Table 1.

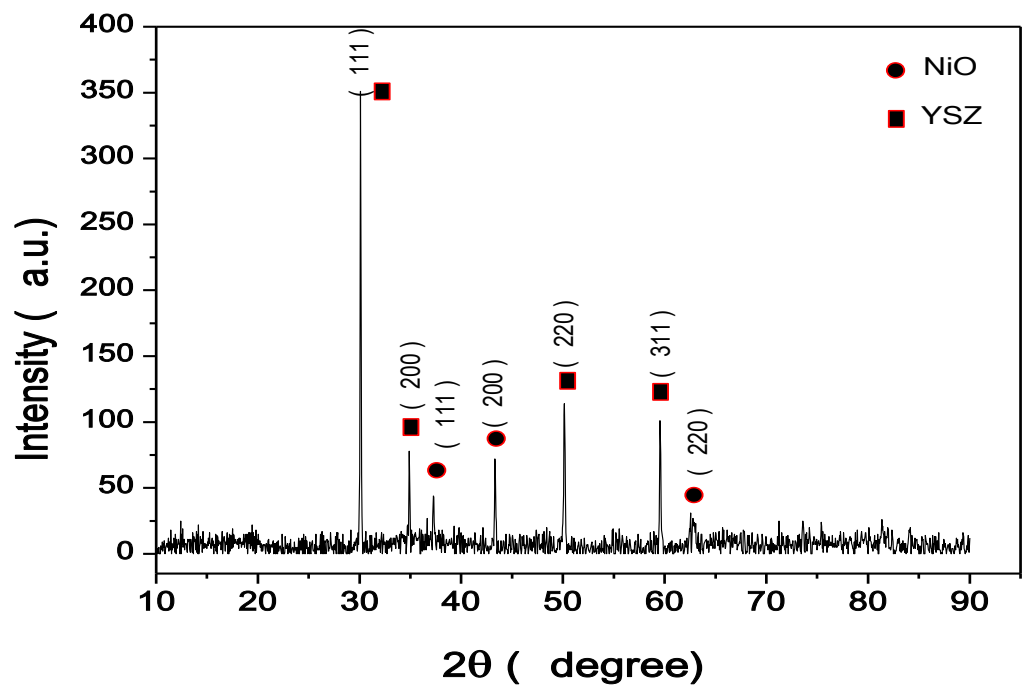

Fig. 1 X-ray diffraction patterns of NiO/YSZ sintered at $1350{ }^{0} \mathrm{C}$ for 5 hours.

The sintered composite contains two crystalline phases, $\mathrm{NiO}$ and YSZ. The sharp diffraction patterns were perfectly matched the crystal structures for NiO and YSZ. From the refinement, it is inferred that YSZ and $\mathrm{NiO}$ are in cubic phase (space group: $\mathrm{Fm} 3 \mathrm{~m}$ ). The cubic phase of $\mathrm{YSZ}$ and $\mathrm{NiO}$ has been indentified from (111) and (200) peaks respectively [16]. The lattice parameters observed for YSZ is $5.139 \AA$, while that for $\mathrm{NiO}$ is $4.176 \AA$. The lattice parameters observed in our sample for YSZ and NiO are matched well with JCPDS file no. 030-1468 and 04-0835 respectively. No peak corresponding to metallic Ni or any other undesirable phases were found within the detection limits of XRD. Crystallite size of NiO and YSZ phases was determined from their respective main peaks using Scherrer's formula [17]:

$$
A=\mathrm{K} \lambda / \beta \cos \theta
$$


where, $K$ is shape factor, $\lambda$ is the wavelength of the $\mathrm{X}$-ray beam (1.5406 $\AA$ ) used, $\theta$ is the angle between the incident beam and reflecting plane, and $\beta$ is the full width at half maximum (FWHM) of the X-ray diffraction peaks.

Crystallite size of YSZ and $\mathrm{NiO}$ in grown powder of $\mathrm{NiO} / \mathrm{YSZ}$ was found to be $84 \mathrm{~nm}$ and $22 \mathrm{~nm}$ respectively. It may be noted here that the average grain size observed from the scanning electron microscopy (SEM) is approximately $800 \mathrm{~nm}$. Reasons for this common discrepancy have been explained in section 3.2.

Table 1 Tabulation of intensity $\left(I_{0}\right)$, observed 'd' value $\left(d_{o}\right)$ / calculated ' $d$ ' value $\left(d_{c}\right)$ obtained from NiO/YSZ sintered specimen refinement.

\begin{tabular}{lcccl}
\hline \multicolumn{1}{c}{$I_{0}$} & $d_{0}$ & $d_{c}$ & $h k l$ & $\begin{array}{l}\text { Reflection rule for } \\
\text { Space group: Fm } 3 m\end{array}$ \\
\hline 351.04 & 2.96604 & 2.96700 & 111 & $h k l: h+k, h+l, k+l=2 n$ \\
77.70 & 2.56931 & 2.56950 & 200 & Okl: $k, l=2 n$ \\
43.70 & 2.40938 & 2.41044 & 111 & $h h l: h+l=2 n$ \\
72.26 & 2.08578 & 2.08750 & 200 & $h 00: h=2 n$. \\
114.42 & 1.81755 & 1.81691 & 220 & \\
102.18 & 1.55142 & 1.54947 & 311 & \\
30.10 & 1.47620 & 1.47609 & 220 & \\
& & & & \\
\hline
\end{tabular}

\subsection{Scanning Electron Microscopy}

Fig. 2 shows the SEM image of the NiO/YSZ composite sintered at $1350{ }^{0} \mathrm{C}$. It is observed from the above figure that the distinct grain growth is occurred. Interlinking between grains is also clearly visible. Nonuniform grain morphology is observed and few pores can also be seen in this figure. Most pores are located at the grain boundaries. It indicates that good contact between YSZ and NiO is achieved during sintering. It appears from the SEM that both small and large grains are co-existed in the composite. Few agglomerations of small size grains are also seen.

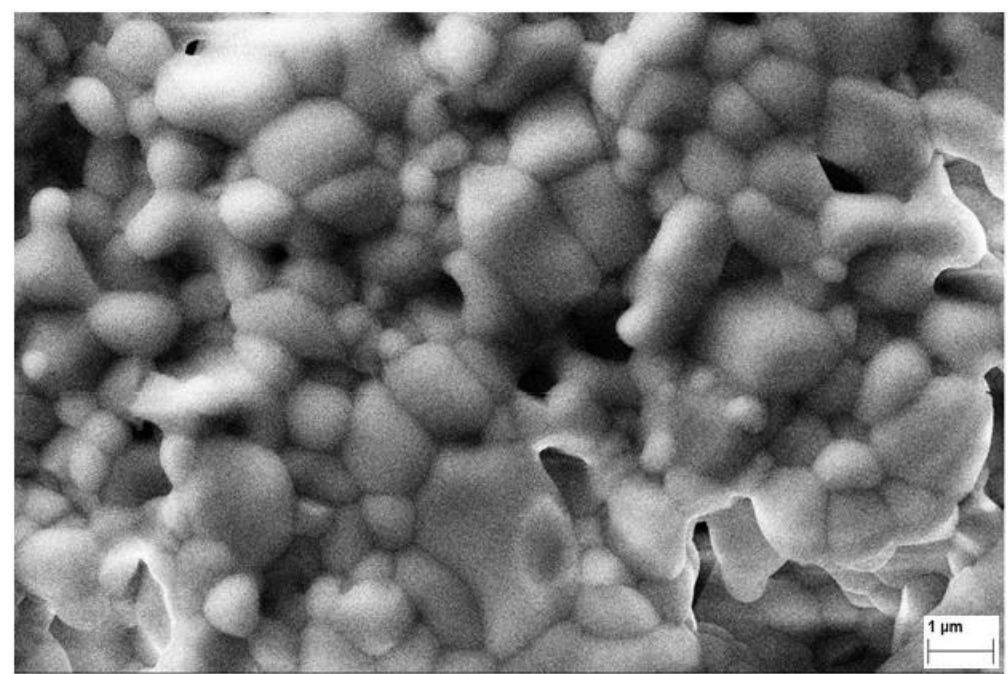

Figure 2 SEM micrograph of NiO/YSZ composite sintered at $1350{ }^{0} \mathrm{C}$ for 5 hours

In case $\mathrm{NiO} / \mathrm{YSZ}$ composites, the surface morphology significantly depends upon the concentration of $\mathrm{NiO}$ and YSZ [16]. The dissolution limit of $\mathrm{NiO}$ in YSZ is the key factor in determining the lattice parameter as well as grain growth habit of the composition. The dissolution of $\mathrm{NiO}$ in YSZ is significantly depends upon the ionic radius and it may be noted that the ionic radius of $\mathrm{Ni}^{2+}$ is small in comparison to both the $\mathrm{Zr}^{4+}$ and $\mathrm{Y}^{3+}$ [16]. The mismatch between ionic radius leads to such non-uniform grain morphology. In this work, our unique synthesis process leads to chemical homogenization of composite. The chemical homogenization influences the microstructure of the product. Hence, we have observed very clear grain boundaries. It may also be noted that in our XRD patterns we have observed both cubic phase for $\mathrm{NiO}$ and YSZ, which leads to two distinct grain morphologies that is the presence of both small and large grains. Furthermore, the grain sizes vary from the submicron to several microns. Grain morphology indicates that the composite is fully dense. 
In some cases, the average grain sizes of grains are matched well with the crystallite size calculated from XRD [18]. However, in present case, both XRD and SEM result differ as mentioned above. It may be due to the formation of agglomerates of small size grains at higher temperature. In other words, the particles in SEM may contain several crystallites [19]. It may also be due to stacking fault or any planar surface defect. Also, in $\mathrm{XRD}$, there may be single crystallite, which is a part of a grain separated from a defect as a coherent domain, smaller in size from SEM, wherein the complete grain is visualized with higher size.

\subsection{X-ray Photoelectron Spectroscopy}

XPS studies were performed to observe the oxidation state of the metal ions in the sintered sample. The chemical valence of $\mathrm{Ni}$ ions in the $\mathrm{NiO} / \mathrm{YSZ}$ composite is shown in Fig. 3(a). We have observed peaks near 870 $\mathrm{eV}$ and $857 \mathrm{eV}$. These peaks belong to $2 \mathrm{p}_{1 / 2}$ and $2 \mathrm{p}_{3 / 2}$ oxidation states of $\mathrm{Ni}$ [20]. The binding energy of Ni2 $\mathrm{p}_{3 / 2}$ peak is higher than the metallic $\mathrm{Ni}_{2} \mathrm{p}_{3 / 2}(852.3 \mathrm{eV})$, indicates $\mathrm{Ni}$ is in positively charged in our composition. The difference between above mentioned peaks is nearly $13 \mathrm{eV}$. Above observations clearly revealed that $\mathrm{Ni}$ is in +2 oxidation state [20,21]. In addition to above, there is also a satellite peak near $864 \mathrm{eV}$, which may be due to the electronic excitations from $3 \mathrm{~d}$ to 4 s level [22].
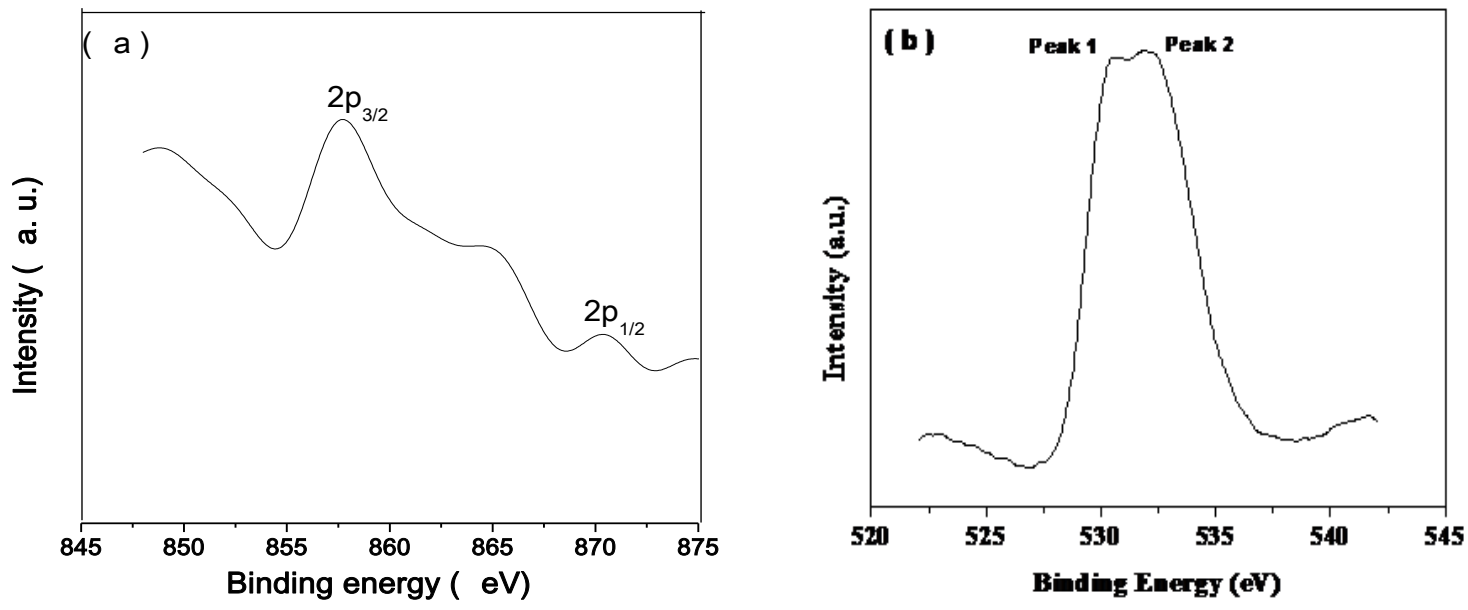

Figure 3 (a) XPS spectrum of $\mathrm{Ni}(2 \mathrm{p}$ ) in NiO/YSZ and (b) XPS spectrum of O(1s) in NiO/YSZ sintered sample.

The XPS spectrum of $\mathrm{O}(1 \mathrm{~s})$ in the sintered NiO/YSZ is shown in Fig. 3(b). Broad and slightly asymmetric nature of the peaks is observed. It may be due to the various coordination of oxygen in the composition [20]. The Peak located near $530 \mathrm{eV}$ (peak 1) and $532 \mathrm{eV}$ (peak 2) correspond to the lattice oxygen and the near-surface oxygen respectively [20]. The peak 2 appears due to the presence of oxygen vacancies (unoccupied sites equivalent to those occupied by lattice oxygen) in the composition NiO/YSZ [20].

Oxygen defect (anion deficiency) in the lattice itself can be expected to make easy transport of oxygen, due to diffusion of oxide ion via vacancies (lattice defect) in the form of oxygen ion-vacancy pair [18]. The mobility of oxygen ion from one vacancy site to another produces a transient dipole. The charge transports within the crystal lattice may be affected on application of external electric field to such a dipole, due to induced dipolar orientation [18]. Special care, therefore, may be taken for analysis of dielectric properties because of arising various problems, due to ionic conduction as follows: (i) ion migration at low frequencies, (ii) contribution to the permittivity due to mobile ions, (iii) electrode polarization due to electrochemical double layer formation at the interface etc [18]. The detail study of oxygen diffusion, ionic conductivity and surface exchange in reducing environments are needed in order to have improved idea of the electro-catalytic properties of the materials [23].

\subsection{Dielectric behavior}

The temperature dependent of dielectric constant for the NiO/YSZ at various frequencies is shown in Fig. 4. It is observed that the dielectric constant is remained constant in low temperature region. Such a low value of dielectric constant in low temperature region indicates the absence of any significant dipolar interaction under the action of applied electric field [18]. However, the dielectric constant is increased sharply in high temperature region. Further to above, the trend of increase of dielectric constant in high temperature region is decreased with the increase of applied frequency. However, the temperature dependent of dielectric constant remains almost constant near $2 \mathrm{MHz}$ frequency. 


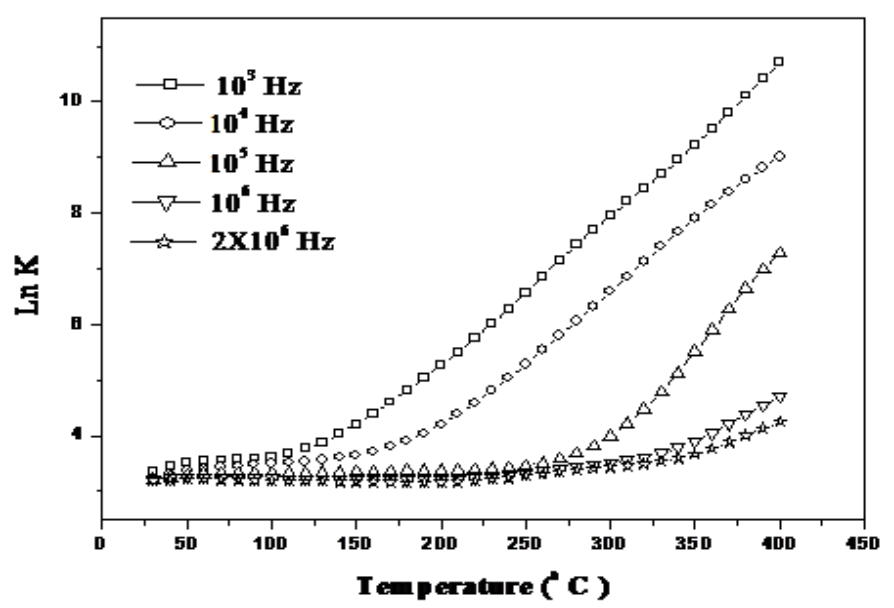

Figure 4 Temperature dependent behavior of dielectric constant at various frequencies for NiO/YSZ sintered sample.

The frequency dependent behavior of dielectric constant at various temperatures is shown in Fig. 5. In general, there are mainly two causes that contribute to dielectric polarization in nonconductors: (i) electronic polarizability (electrons shifting within molecules) and (ii) orientational polarizability (dipolar molecules rotating or flipping, or ions changing places). At low frequency, electronic polarizability and orientational polarizability contribute to dielectric constant. At high frequency, dielectric constant just results from the electron displacement polarization [24]. The first effect has rather weak temperature dependence, the second a rather pronounced one [25]. The frequency independent of dielectric constant indicates the presence of the random diffusion of charge carriers via activated hopping [25].

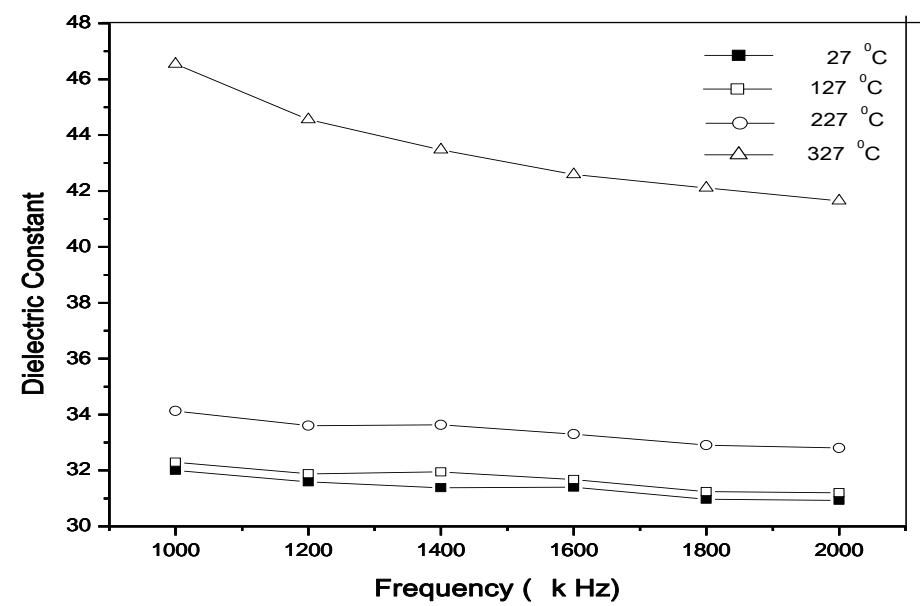

Figure 5 Frequency dependent behavior of dielectric constant at various temperatures for NiO/YSZ sintered sample.

However, the frequency dependency indicates the presence of a non-random process, where the ions perform correlated forward- backward motion. The switch from frequency dependence to frequency independency in high temperature region may be due to the onset of dipolar relaxation phenomena [13]. It also indicates that the translation from short range cluster motion to long range hopping effect, which leading to an increase in dielectric response in high temperature region [13]. We have observed oxygen vacancies in Fig. 3(b) and the oxygen vacancies are the key factors for observation of such dielectric behavior [13]. The dipolar response appears to be enhanced significantly with increasing of oxygen vacancies in the grain boundary core [13].

Fig. 6 shows the temperature dependence of dielectric constant and dielectric loss at frequency $10^{5} \mathrm{~Hz}$ for $\mathrm{NiO} / \mathrm{YSZ}$ sample. Both are remained temperature independent in low temperature region and then rapidly increase with increasing the temperature. This sharp increase of dielectric loss in a high temperature region may 
be attributed to the increased mobility of charge carriers due to defects or vacancies in the sample [26]. Both, dielectric constant and dielectric loss are also high at lower frequency, but falls with rising frequency, shown in Fig. 7. It indicates the presence of dipolar relaxation phenomena in our composition. Purpose of re-plotting of not only $\mathrm{K}$ but also tan $\delta$ at $10^{5} \mathrm{~Hz}$ is to observe the nature of variation at higher frequency from which both $\mathrm{K}$ and $\tan \delta$ variation becomes constant which normally observed from the frequency dispersion curve of $\mathrm{K}$ and $\tan \delta$. This onset of constant $\mathrm{K}$ and $\tan \delta$ normally started from $10^{5} \mathrm{~Hz}$ where we have assigned the contribution of electron displacement polarization [24].

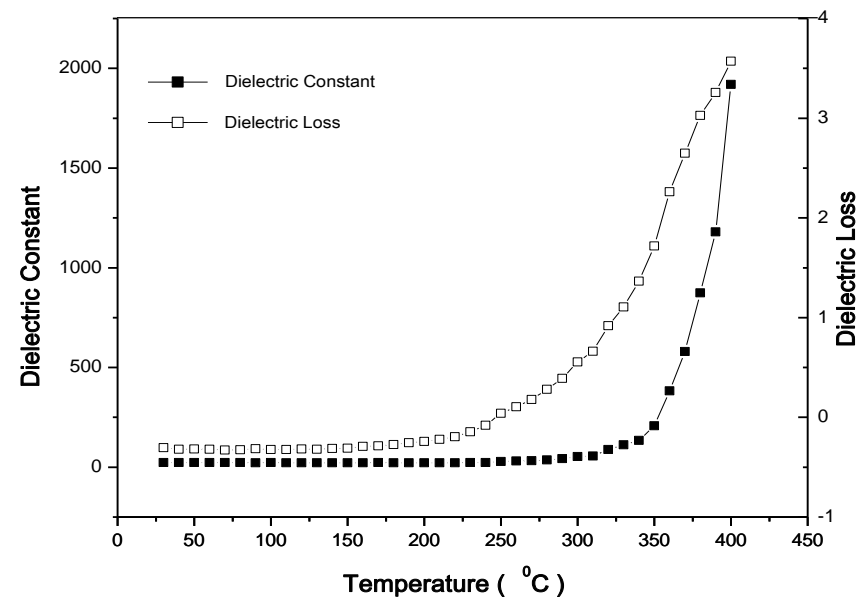

Figure 6 Dielectric constant and Dielectric loss versus Temperature curves at frequency $10^{5} \mathrm{~Hz}$ for NiO/YSZ sintered sample.

A diversified effort has been made to understand the conduction mechanism in SOFC using different characterization techniques [25]. One of the strategies for understanding the electrode performance is to know the charge transport mechanism with the temperature and frequency [25]. The study of the frequency and temperature dependency of dielectric constant may provide an opportunity to understand the details of electronic/ionic migration mechanism [25].

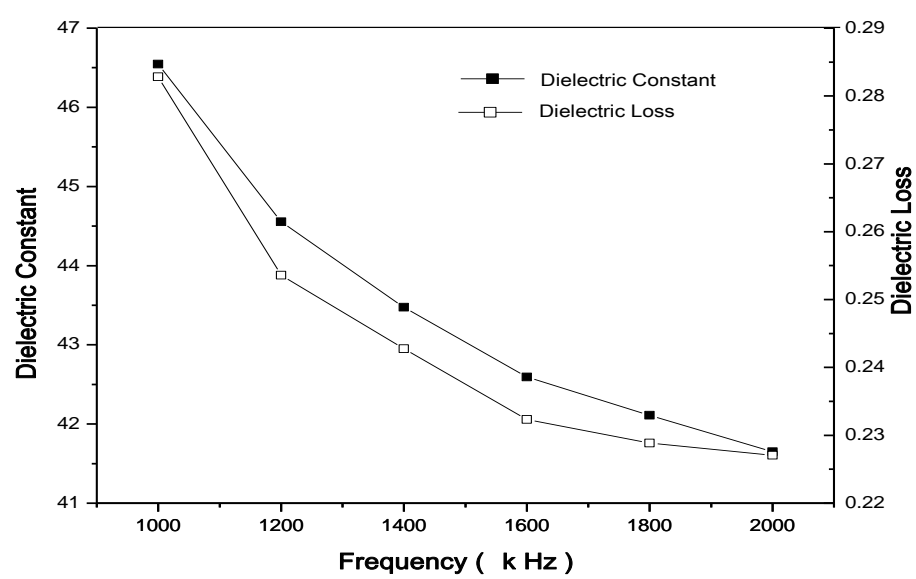

Figure 7 Dielectric constant and Dielectric loss versus Frequency curves at temperature $600 \mathrm{~K}$ for NiO/YSZ sintered sample.

\subsection{Conductivity}

The observations show that the behavior of conductivity as a function of temperature is of nearly equal nature within our range of frequencies. The Arrhenius plot for electrical conductivity of NiO/YSZ composite at frequency $2 \mathrm{MHz}$ is merely shown in Fig. 8. The activation energy for the conduction process is calculated from the slope of the line according to Arrhenius equation [27]:

$$
\sigma=A \exp \left(-E_{a} / \mathrm{K}_{\mathrm{B}} T\right)
$$

where, $A$ is the pre-exponential factor, $E_{a}$ is the activation energy, $\mathrm{K}_{\mathrm{B}}$ is the Boltzmann constant and $T$ is the absolute temperature. There is a mixed conductivity [28, 29] containing an ionic and an electronic component. 
The increase in conductivity with temperature may be attributed to the anion vacancies (holes) which are activated at high temperature since more activation energy is required for them than electrons. Conduction in higher temperature region is due to holes as well as electrons whereas in lower temperature region it is mainly due to electrons only [30]. The activation energies were calculated to be $0.04 \mathrm{eV}$ and $0.42 \mathrm{eV}$ for lower $\left(27^{\circ} \mathrm{C}\right.$ $\left.227^{\circ} \mathrm{C}\right)$ and higher $\left(227^{\circ} \mathrm{C}-327^{\circ} \mathrm{C}\right)$ temperature region respectively. At lower temperature, the smaller activation energy may be attributed to hopping process of electrons between ions of different valences [31]. A low electrical conductivity in the sample may be due to high grain boundary density [29]. It may be noted that there are three basic properties [3, 11, 32-34] of an anode for SOFC's applications. These are (i) it oxidizes the fuel, (ii) it acts as catalyst for reforming the fuel, and (iii) it helps electrons to conduct in the external circuit. However an anode material must have high electrical conductivity, dimensional and chemical stability, high electrochemical or catalytic activity, high porosity and compatible with other cell components.

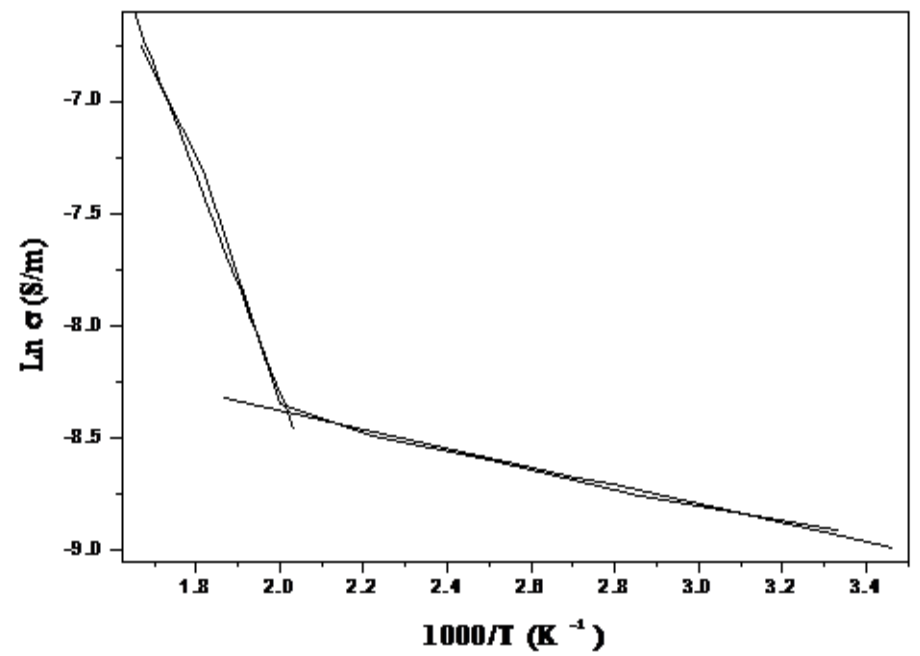

Figure 8 Arrhenius plot for conductivity of sintered NiO/YSZ composite at frequency $2 \mathrm{MHz}$.

Further to above, the physical compatibility includes the consistent of thermal expansion coefficient and thermal stress caused by the temperature change, with other materials of SOFC. Whereas, Chemical compatibility needs no mass diffusion and contact reactions in interfaces between other parts of fuel cell, within working temperature, to avoid increase of resistance loss. The catalytic activity attributes to quick exchange of charges and further decrease of resistance and over potential losses. Hence, electro-catalytic activity and thermal activation play crucial role in low and high temperature fuel cells respectively, to enhance charge transportation in improving anodic performance [11, 23, 35].

It is appropriate to discuss here at high temperature, $\mathrm{NiO}$ and YSZ do not form solid solution, this can be sintered to form $\mathrm{NiO} / \mathrm{YSZ}$ composite and finally reduced to form a porous $\mathrm{Ni} / \mathrm{YSZ}$ cermet to enhance its conductivity. Though, there are huge advantages of this material as SOFC anode, some drawbacks are connected as follows: (i) poor redox stability, (ii) carbon deposition when hydrocarbon fuels are used, and (iii) tendency of nickel agglomeration after prolonged operation [35]. In spite of drawbacks discussed above, $\mathrm{Ni} / Y S Z$ is the most preferred anode materials among others for SOFCs for its acceptable physical and chemical stability [11].

From above result and discussion, two different transport mechanism leading to mixed electrical conductivity are envisaged: (i) short range transport mechanism, originates from hopping process of charge carriers (holes and/or electrons) between different ions in localized states around Fermi level at low temperature, resulting lower activation energy; and (ii) long range transport mechanism, originates from thermally activated charge carriers into extended state at higher temperature, resulting higher activation energy [36].

\section{Conclusions}

In summary, the hopping type conduction and dielectric phenomena have been investigated systematically for our sample $\mathrm{NiO} / \mathrm{YSZ}$. The dielectric constant is increased sharply in high temperature region. However, the trend of increase of dielectric constant in high temperature region is decreased with the increase of applied frequency and it is remained almost constant for high frequency. In case of the dielectric loss, it is remained temperature independent in low temperature region and then rapidly increases with increasing the temperature. The dipolar relaxation phenomenon is also responsible for the observation of such dielectric loss. The oxygen vacancy is the key factor for the observation of above type of dielectric behavior. In the lower temperature region, the conductivity of $\mathrm{NiO} / \mathrm{YSZ}$ composite is relatively low. This may be due to high grain 
boundary density, which results increased grain boundary resistance. The study of both micro structural and electrical properties of prepared NiO/YSZ composite suggests the suitability of our preparation method for fabrication of precursor for SOFC anode. Temperature dependent high frequency $(\approx \mathrm{MHz}$ range) conductivity of $\mathrm{NiO} / \mathrm{YSZ}$ composite reveals the presence of mixed conductivity i.e., ionic conductivity in high temperature range and electronic conductivity in low temperature range. Present observation reveals anodic suitability of $\mathrm{NiO} / \mathrm{YSZ}$ composite for possible SOFC application. It is expected that high temperature reduction in hydrogen atmosphere will further improve the anodic properties required for SOFC applications.

\section{Acknowledgements}

Author, V. Mohanta, acknowledges to the Director, Institute of Materials Science, Bhubaneswar, Odisha, India for providing experimental facilities to carry out this research work and Institute of Minerals and Materials Technology, Bhubaneswar for the synthesis of samples. The authors are also very much thankful to Institute of Physics, Bhubaneswar, India for the SEM and XPS measurements. The authors would also like to thank the Department of Physics, Utkal University, Bhubaneswar, India for carrying out XRD measurements.

\section{References}

[1]. H. Mohebbi, T. Ebadzadeh, and F. A. Hesari, Synthesis of nano-crystalline NiO-YSZ by microwave- assisted combustion synthesis, Power Technol., 188(3), 2009, 183-186.

[2]. N. F. P. Ribeiro, M. M. V. M. Souza, O. R. M. Neto, S. M. R. Vasconcelos, and M. Schmal, Investigating the microstructure and catalytic properties of Ni/YSZ cermets as anodes for SOFC applications, Appl. Catalysis A: General, 353(2), 2009, $305-309$.

[3]. G. Singh and K. L. Singh, Characterization of NiO-YSZ nanocomposite synthesized by combustion method, Int. J. for Sci. and Emerg. Technol., 3(1), 2012, 1-8.

[4]. S. C. Singhal and K. Kendall, High Temperature Solid Oxide Fuel Cells: Fundamentals, Design and Applications (1 ${ }^{\text {st }}$ edition, Elsevier, 2003).

[5]. B. Riley, Solid oxide fuel cells — the next stage, J. Power Sources, 29(1-2), 1990, 223-237.

[6]. N. Q. Minh, Ceramic Fuel Cells, J. of Am. Ceram. Soc., 76(3), 1993, 563-588.

[7]. S. P. Jiang and S. H. Chan, A review of anode materials development in solid oxide fuel cells, J. of Mater. Sci., 39(14), 2004, 44054439.

[8]. N. Q. Minh and T. Takahashi, Science and Technology of Ceramic Fuel Cells (1 ${ }^{\text {st }}$ edition, Elsevier, 1995).

[9]. J. H. Lee, H. Moon, H. W. lee, J. Kim, J. D. Kim, and K. H. Yoon, Quantitative analysis of microstructure and its related electrical property of SOFC anode, Ni-YSZ cermet, Solid State Ionics, 148(1-2), 2002, 15-26.

[10]. S. P. Jiang, Sintering behavior of $\mathrm{Ni} / \mathrm{Y}_{2} \mathrm{O}_{3}-\mathrm{ZrO}_{2}$ cermet electrodes of solid oxide fuel cells, J. Mater. Sci., 38(18), 2003, $3775-3782$.

[11]. W.Z. Zhu, S. C. Deevi, A review on the status of anode materials for solid oxide fuel cells, Mater. Sci. and Eng. A, 362(1-2), 2003, 228-239.

[12]. H. Tu and U. Stimming, Advances, aging mechanisms and lifetime in solid-oxide fuel cells, J. Power Sources, 127(1-2), 2004, 284293.

[13]. T. Priyatham and R. Bauri, Synthesis and characterization of nanocrystalline Ni-YSZ cermet anode SOFC, Mater. Charact., 61(1), 2010, 54-58.

[14]. C. A. da Silva, N. F. P. Riberio, and M. M. V. M. Souza, Effect of the fuel type on the synthesis of yttria stabilized zirconia by combustion method, Ceram. Int., 35(8), 2009, 3441-3446.

[15]. B. K. Roul, Modulated structural characteristics and microwave properties of spray pyrolyzed superconducting BCSCO, J. of Supercond., 14(4), 2001, 529.

[16]. K. L. Singh, A. Kumar, A. P. Singh, and S. S. Sekhan, Microwave processing: A potential technique for preparing NiO-YSZ composite and Ni-YSZ cermet, Bull. Mater. Sci., 31(4), 2008, 655-664.

[17]. X. Xi, H. Abe, M. Naito, Effect of composition on microstructure and polarization resistance of solid oxide fuel cell anode NiOYSZ composite made by co-precipitation, Ceram. Int., 40(10), 2014, 16549-16555.

[18]. N. Pandey, A. K. Thakur, and R. N. P. Choudhary, Studies on dielectric behabiour of an oxygen ion conducting ceramic$\mathrm{CaMnO}_{3-\delta}$, Indian J. of Eng. \& Mater. Sci., 15(2), 2008, 191-195.

[19]. A. Gaber, M. A. Abdel- Rahim, A. Y. Abdel-Latief, and M. N. Abdel-Salam, Influence of Calcination Temperature on the Structure and Porosity of Nanocrystalline $\mathrm{SnO}_{2}$ Synthesized by a Conventional Precipitation method, Int. J. of Electrochem. Sci., 9(1), 2014, 81-95.

[20]. S. K. Das, R. N. Mishra, and B. K. Roul, Magnetic and ferroelectric properties of Ni doped BaTiO 3 , Solid State Commun., 191, 2014, 19-24.

[21]. Q. Xu, W. Chen, and R. Yuan, XPS analysis of Ni and Oxygen in single- sintered $\mathrm{SrTiO}_{3}$ multifunction ceramic, J. Mater. Sci. Technol., 17(5), 2001, 535-537.

[22]. G. K. Wertheim and S. Hufner, X-ray Photoemission Band structure of some Transition-Metal Oxides, Phys. Rev. Lett., 28(16), 1972, 1028.

[23]. A. Atkinson, S. Barnett, R. J. Gorte, J. T. S. Irvine, A. J. Mc Evoy, et al, Advanced anodes for high-temperature fuel cells, Nature Materials, 3(1), 2004, 17-27.

[24]. S. K. Das, R. N. Mishra, and B. K. Roul, Diluted magnetic ferroelectric effect in $\mathrm{BaTi}_{0.9} \mathrm{Hf}_{0.05} \mathrm{Co}_{0.05} \mathrm{O}_{3} \mathrm{ceramic}$ Appl. Phys. A, 116(4), 2014, 1897-1903.

[25]. R. F. Martines, M. C. Brant, R. Z. Domingues, R. M. Paniago, K. Sapag, et al, Synthesis and characterization of NiO-YSZ for SOFCs, Mater. Res. Bull., 44(2), 2009, 451-456.

[26]. V. S. Yadav, D. K. Sahu, Y. Singh and D. C. Dhubkarya, The effect of frequency and temperature on dielectric properties of pure poly vinylidene fluoride (PVDF) thin films, Proceedings of International Conference of Engineers and Computer Scientist, EMECS Vol 3, Hongkong, 2010.

[27]. L. K. Sudha, S. Roy and K. Uma Rao, Evaluation of Activation Energy (Ea) Profiles of Nanostructured Alumina Polycarbonate Composite Insulation Materials, Int. J. of Mater. Mech. and Manuf., 2(1), 2014, 96-100.

[28]. Y. M. Park and G. M. Choi, Mixed ionic and electronic conduction in YSZ-NiO composite, J. of Electro Soc., 146(3), 1999, 883889. 
[29]. P. Duran, J. Tartaj, F. Capel, and C. Moure, Processing and characterization of a fine nickel oxide/ zirconia/composite prepared by polymeric complex solution synthesis, J. of Eur. Ceram. Soc., 23(12), 2003, 2125-2133.

[30]. M. Manikandan and C. Venkateswaran, Effect of high energy milling on the synthesis temperature, magnetic and electrical properties of barium hegagonal ferrite, J. of Magn.Magn. Mater. 358-359, 2014, 82-86.

[31]. M. A. Gabal, A. M. Abdel-Daiem, Y. M. Al Angari, and I. M. Ismail, Influence of Al-substitution on structural, electrical and magnetic properties of Mn-Zn ferrites nanopowders prepared via the sol-gel auto-combution method, Polyhedron, 57, 2013, 105111.

[32]. Z. C. Chen, Y. Sakane, T. Tsurumaki, Y. Ayame, and F. Fujita, Microstructure and electrical conductivity of Ni/YSZ cermets for SOFC, $16^{\text {th }}$ International conference on composite materials, Kyoto, Japan, 2007.

[33]. G. Matula, T. Jardiel, R. Jimenez, and B. Levenfeld, Microstructure, mechanical and electrical properties of Ni-YSZ anode supported solid oxide fuel cells, Archit. of Mater. Sci. and Eng., 32(1), 2008, 21-25.

[34]. K. Sato, M. Naito, and H. Abe, Electrochemical and mechanical properties of solid oxide fuel cell Ni/YSZ anode fabricated from $\mathrm{NiO} / \mathrm{YSZ}$ composite powder, J. of Ceram. Soc. of Japan, 119(11), 2011, 876-883.

[35]. C. Sun and U. Stimming, Recent anode advances in solid oxide fuel cells, J. of Power Sources, 171(2), 2007, 247-260.

[36]. E. Senturk, Y. Koseoglu, T. Sasmaz, F. Alan, and M. Tan, RC circuit and conductivity properties of $\mathrm{Mn}_{0.6} \mathrm{Co}_{0.4} \mathrm{Fe}_{2} \mathrm{O}_{4}$ nanocomposite synthesized by hydrothermal method, J. Alloys Compd., 578, 2013, 90-95. 